\title{
Use of cyclodextrins to recover catechin and epicatechin from red grape pomace
}

\author{
Santiago López-Miranda*, Ana Serrano-Martínez, Pilar Hernández-Sánchez, Lucía Guardiola, \\ Horacio Pérez-Sánchez, Isabel Fortea, José Antonio Gabaldón, Estrella Núñez-Delicado \\ Department of Food Technology \& Nutrition, UCAM Universidad Católica de Murcia, Avenida de los Jerónimos s/n, 30107 Guadalupe, Murcia, Spain
}

\section{A R T I C L E I N F O}

\section{Article history:}

Received 1 September 2015

Received in revised form 14 December 2015

Accepted 13 February 2016

Available online 15 February 2016

\section{Keywords:}

Catechin

Epicatechin

Grape pomace

Cyclodextrin

\begin{abstract}
A B S T R A C T
The capacity of cyclodextrins (CDs) to extract phenolic compounds from grape pomace was evaluated and compared with that of ethanol/water or aqueous extraction. The extraction method (stirring and ultrasound), temperature and time were also studied. Total phenolic compounds (TPC) and antioxidant activity were measured, and HPLC analysis was used to identify the phenolic compounds. The extracts obtained using the ethanol/water mixture presented the highest TPC content and antioxidant activity, followed by those obtained using CD solutions. The addition of CDs to the extractant agent had a selective effect on the extraction of catechin and epicatechin. The yield of catechin and epicatechin by using aqueous solutions of CDs was similar to that obtained using organic solvents as ethanol.
\end{abstract}

(C) 2016 Elsevier Ltd. All rights reserved.

\section{Introduction}

The interest in using or reusing wine by-products, particularly grape pomace, has resulted in the development of different applications including yeast production, seed oil extraction, energy production, decontamination of effluents with a high metal content, and compost production (Bustamante et al., 2008). In addition, grape pomace is a rich source of several high value added products, such as ethanol, citric acid, tartrates, oil seed, hydrocolloids, fiber dietary and phenolic compounds (Arvanitoyannis, Ladas, \& Mavromatis, 2006).

Grape phenolic compounds are responsible for some of the most important wine properties, in particular color, astringency, flavor and body (Lafka, Sinanoglou, \& Lazos, 2007). Wine phenolic compounds, particularly flavanols, have been intensely studied due to their relationship with the beneficial effects of moderate wine consumption on human health (Arvanitoyannis et al., 2006; Louli, Ragoussis, \& Magoulas, 2004; Maier, Schieber, Kammerer, \& Carle, 2009). Large quantities of these phenolic compounds are retained in the pomace after the elaboration of the wine (Makris, Boskou, \& Andrikopoulos, 2007), which is why their recovery is of interest for the food, pharmaceutical and cosmetic industries.

Phenolic compounds with the greatest presence in grape pomace are the flavan-3-ols, catechin and epicatechin, and gallic

\footnotetext{
* Corresponding author.

E-mail address: slmiranda@ucam.edu (S. López-Miranda).
}

acid (Lafka et al., 2007; Tsanova-Savova, Ribarova, \& Gerova, 2005). Flavanols, which are mainly located in seeds (Kennedy, Sauicier, \& Glories, 2005), are the phenolic compounds responsible for wine bitterness and astringency. Catechin and epicatechin can represent up to $60 \%$ of total phenolic compounds present in grape seed (Chedea, Braicu, \& Socaciu, 2010). As regards antioxidant capacity, this could be greater than that of other minor compounds such as resveratrol or rutin (Iacopini, Baldi, Storchi, \& Sebastiani, 2008). The role of flavanols in the prevention of cancer and cardiovascular diseases has received a lot of attention (Jang et al., 1997; Kuroda \& Hara, 1999; Shrikhande, 2000).

The extraction of phenolic compounds is the first step to their use in industry. In general, solid-liquid extraction has been the most used extraction method, combining different types of organic solvents such as methanol, ethanol, acetone, ethyl acetate (Lafka et al., 2007). Other new extraction technologies studied include supercritical fluids (Da Porto, Natolino, \& Decorti, 2014; Herrero, Cifuentes, \& Ibañez, 2006), extraction assisted by electrical pulses (Bucic-Kojic, Sovová, Planinic, \& Srecko, 2013; Sánchez, Sineriro, and Núñez, 2008) and polymeric adsorber resins (Kammerer \& Kljusuric, 2005). However, such extraction techniques usually use organic solvents that are toxic for human, or the technology and equipment needed is too expensive or complex for use at an industrial level (Ratnasooriya \& Rupasinghe, 2012). Replacing organic extraction solvents by exclusive aqueous extractions without affecting the extraction yield is one of the most pressing problems to be solved in the extraction of phenolic compounds from grape by-products. 
The use of CDs for this purpose has received comparatively little attention to date, although their ability to encapsulate compounds of different nature has been widely studied. Several studies have shown that CDs can increase the solubility of phenolic compounds in water (Lucas-Abellán, Fortea, Gabalón, \& Núñez-Delicado, 2008; Mercader-Ros, Lucas-Abellán, Fortea, Gabaldón, \& Núñez-Delicado, 2010; Mercader-Ros et al., 2010). It therefore seemed likely that the use of aqueous solutions of CDs could improve the extraction of phenolic compounds with a polarity and structure compatible with the CD cavity, enabling these compounds to be extracted without the assistance of organic solvents. Complexation with CDs also protects against oxidation and could improve the stability of the phenolic compounds complexed.

The aim of this work was to evaluate the capacity of CDs to contribute to the extraction of the phenolic compounds present in wine pomace, especially the main compounds catechin and epicatechin.

\section{Material and methods}

\subsection{Samples preparation}

Grape pomace from Monastrel variety (Vitis vinifera L.) was provided by Bodegas San Isidro located in Jumilla (Spain). Samples were collected immediately after wine pressing and stored at $-80{ }^{\circ} \mathrm{C}$ until laboratory extraction and determination.

\subsection{Reagents and standards}

Methanol and water were HPLC grade and purchased from JT Baker (The Netherlands). Ethanol and hexane of HPLC grade, and $\mathrm{Na}_{2} \mathrm{CO}_{3}$ were purchased from Panreac (Germany). Phenolic standards (gallic acid, catechin and epicatechin) (purity of 98-99\%), Folin-Ciocalteau phenol reagent were purchased from Sigma Chemical Co. (Great Britain). $\beta$ - and HP- $\beta$-CDs were purchased form Winplus International Limited (China). APPH were purchase from Aldrich Chemistry (San Luis, USA).

\subsection{Extraction of phenolic compounds}

Prior to phenolic compound extraction, the fresh grape pomace was ground in a coffee grinder for $20 \mathrm{~s}$, defatted by two-step extraction for $15 \mathrm{~min}$ with $\mathrm{n}$-hexane at a ratio of $10: 1(\mathrm{v} / \mathrm{w})$ in an orbital shaker Bunsen MC8 (Spain) at $2100 \mathrm{rpm}$ and $25^{\circ} \mathrm{C}$, and dried in an oven at $50^{\circ} \mathrm{C}$ for $24 \mathrm{~h}$.

The extraction of the phenolic compounds was performed in a mixture of ethanol:water $1: 1(\mathrm{v} / \mathrm{v})$, water or aqueous solutions of $\beta$ - or HP- $\beta$-CDs ( 8 and $13 \mathrm{mM} \beta$-CDs; 13,25 and $50 \mathrm{mM} \mathrm{HP-} \beta-$ $\mathrm{CDs}$ ) for different extraction times (from 1 to $90 \mathrm{~min}$ ), at two different extraction temperatures $\left(25\right.$ or $40^{\circ} \mathrm{C}$ ), stirring in an orbital shaker (P-Selecta Mutimatic 9N, Spain) or by ultrasound (P-Selecta Ultrasons, Spain). The $\mathrm{pH}$ of all extractions solvents were adjusted to 1.5 using $\mathrm{HCl}$. All extractions were made in a 9:1 (v/w) proportion of solvent volume to sample mass. The extracts were centrifuged in a microcentrifuge (Eppendorf Centrifuge S415D, Germany) at $10,000 \mathrm{~g}$ for $1 \mathrm{~min}$ and filtered using $0.45 \mu \mathrm{m}$ nylon filters (Chromafil, Germany). Extracts centrifuged and filtered were used for phenolic content and antioxidant activity determinations, and for HPLC analysis. All extractions, determinations and analysis were made in triplicate.

\subsection{Phenol content determination}

The total phenolic content (TPC) of grape pomace extracts was determined colorimetrically at $765 \mathrm{~nm}$ using the Folin-Ciocalteau reagent according to a modification of the Kidron, Harel, and
Mayer (1978) method. Folin-Ciocalteau reaction was made mixing $100 \mu \mathrm{L}$ of diluted grape pomace extract $(1 / 10 \mathrm{v} / \mathrm{v}$ extract/water), $150 \mu \mathrm{L}$ of Folin Ciocalteau reagent, $450 \mu \mathrm{L}$ of $20 \% \mathrm{Na}_{2} \mathrm{CO}_{3}$ and $2300 \mu \mathrm{L}$ of distilled water. After $2 \mathrm{~h}$ of reaction, the absorbance of the sample was measured against a blank by using a spectrophotometer (Shimadzu model UV-1603, Japan). The calibration curve was made using gallic acid as standard, measuring the absorbance at $765 \mathrm{~nm}$ of $0,2,4,6$ and $8 \mu \mathrm{g} / \mathrm{mL}$ of gallic acid. TPC is expressed in $\mathrm{mg}$ of gallic acid equivalents per gram of dry pomace $\left(\mathrm{mg} / \mathrm{g}_{\mathrm{db}}\right)$ and determinations were made in triplicate.

\subsection{Antioxidant activity (ORAC method)}

The ORAC analyses were carried out on a Synergy HT multidetection microplate reader, from Bio-TekInstruments, Inc. (USA), using 96-well polystyrene microplates with black sides and clear bottoms. Fluorescence was read through the clear bottom, with an excitation wavelength of $485 / 20 \mathrm{~nm}$ and an emission filter of $528 / 20 \mathrm{~nm}$. The plate reader was controlled by KC4, version3.4, software. The oxygen radical absorbance capacity was determined as described by Dávalvos with slight modifications (Dávalvos, Gómez-Cordovés, \& Bartolomé, 2004). The reaction was carried out in $75 \mathrm{mM}$ sodium phosphate buffer ( $\mathrm{pH} 7.4$ ), and the final reaction mixture was $200 \mu \mathrm{L} .100 \mu \mathrm{L}$ fluorescein ( $3 \mathrm{nM}$, final concentration) and $70 \mu \mathrm{L}$ of diluted grape pomace extract ( $1 / 100 \mathrm{v} / \mathrm{v}$ extract/ water) were placed in the wells of the microplate. The mixture was preincubated for $30 \mathrm{~min}$ at $37^{\circ} \mathrm{C}$, before rapidly adding the AAPH solution ( $30 \mu \mathrm{L} ; 19 \mathrm{mM}$, final concentration) using a multichannel pipette. The microplate was immediately placed in the reader and the fluorescence recorded every $1.14 \mathrm{~min}$ for $120 \mathrm{~min}$. The microplate was automatically shaken prior to each reading. A blank with fluorescein and AAPH using sodium phosphate buffer instead of the antioxidant solution and eight calibration solutions using Trolox $C(6.25,12.5,15,18.75,21.25,25,27.5$ and $31.25 \mu \mathrm{M})$ as antioxidant were also used in each assay. All reaction mixtures were prepared in triplicate and at least three independent assays were performed for each sample. In order to avoid a temperature effect, only the inner 60 wells were used for experimental purposes, while the outer wells were filled with $200 \mu \mathrm{L}$ of distilled water. The results were expressed as relative fluorescence with respect to the initial reading. The net AUC corresponding to the sample was calculated by subtracting the AUC corresponding to the blank. Determinations of antioxidant activity were made for triplicate.

\subsection{HPLC analysis}

Identification and quantification of phenolic compounds of the grape pomace extracts was performed by HPLC analysis using an HPLC Agilent Technologies model 1200 equipped with a variable DAD detector set at $280 \mathrm{~nm}$. $20 \mu \mathrm{L}$ of centrifuged and filtered extract were injected. Separations were achieved on an endcapped (5 $\mu \mathrm{m}$ ) HPLC Cartridge 250-4 LiChospher $100 \mathrm{RP}-18$. The flow rate was $1 \mathrm{~mL} / \mathrm{min}$. The mobile phase used was $0.5 \%$ formic acid in water (A) versus methanol (B) for a total running time of $60 \mathrm{~min}$ and the gradient changed as follows: solvent $B$ started at $2 \%$, then increased to $32 \%$ in $30 \mathrm{~min}$, to $40 \%$ in $10 \mathrm{~min}$, to $95 \%$ in $10 \mathrm{~min}$, and returned to initial conditions in $10 \mathrm{~min}$. The data were processed by Agilent ChemStation software. Catechin and epicatechin is expressed in $\mu \mathrm{g}$ per gram of dry pomace $\left(\mu \mathrm{g} / \mathrm{g}_{\mathrm{db}}\right)$ and determinations were made in triplicate.

\subsection{Molecular model}

The molecular structures for catechin and epicatechin used in this study were built manually using AutoDockTools (Morris 
et al., 2009) and structural information derived from experimental data. The structure of $\beta$-CDs was extracted from the crystal structure of the Protein Data Bank (PDB) with code 3CGT. Molecular docking calculations were carried out using default parameters in AutoDockVina (Trott \& Olson, 2010). Graphical representations of the docking results were prepared using PyMOL (Molecular Graphics System, version 1.3, Schrödinger, LLC).

\subsection{Statistical analysis}

Data were analysed by using one way analysis of variance (ANOVA) of the statistical analysis software SPSS (v.21). Significant differences between means were analysed by using the Tukey test.

\section{Results and discussion}

\subsection{Total phenolic compounds (TPC) and antioxidant activity}

The TPC extracted and the antioxidant activity of the extracts obtained using different solvents as extract agents, as well as two extraction energy sources, stirring and ultrasound, both at $25^{\circ} \mathrm{C}$, are shown in Table 1.

The ethanol/water mixture provided the highest extraction yield of TPC and antioxidant activity. The TPC values obtained were $21.2 \mathrm{mg} / \mathrm{g}_{\mathrm{db}}$ (dry base) and $23.5 \mathrm{mg} / \mathrm{g}_{\mathrm{db}}$ for stirring and ultrasounds extraction, respectively (Table 1 ). These values were similar to those observed by Louli et al. (2004) (26 mg/g) and lower than those obtained by Lafka et al. (2007) (35 mg/g) and Negro, Tommasi, and Miceli (2003) (41 mg/g). With respect to antioxidant activity, the ethanol/water extracts presented 42.1 and $48.1 \mathrm{mM}$ Trolox for the stirring and ultrasounds extraction methods, respectively.

The extraction energy applied (stirring or ultrasound) affected TPC extraction. As an average of all the extractions, the TPC and antioxidant activity of the extracts were, respectively, $14 \%$ and $21 \%$ higher in those obtained by using ultrasound than when using the stirring method (Table 1). Although this tendency was observed in all solvents studied, differences between stirring and ultrasound methods were only statistical significant in 6 of the 14 cases studied. The fact that the improvement in antioxidant activity was higher (21\%) than the improvement in TPC extraction (14\%) indicates that ultrasound extraction improves the extraction of phenolic compounds with a greater relative antioxidant activity.

Removing the organic solvents from the extraction agent had a negative effect on phenolic extraction. When water was used as extraction agent, the TPC extracted was $3.67 \mathrm{mg} / \mathrm{g}_{\mathrm{db}}$ and $4.18 \mathrm{mg} /$ $\mathrm{g}_{\mathrm{db}}$ for stirring and ultrasound, respectively, $82 \%$ lower than the values obtained with ethanol/water extraction (Table 1 ). These values were slightly higher than those observed by Bustamante et al.
(2008) for aqueous extractions. The antioxidant activity of aqueous extracts was $82 \%$ lower than that presented in ethanol/water extracts for both the stirring and ultrasound methods.

In an attempt to increase the levels of TPC extracted from grape pomace in the absence of organic solvents, aqueous solutions of $\beta$ or HP- $\beta-C D$ s were used. When CDs were added to the extraction water, an increase in the TPC extracted was observed, as well as in antioxidant activity of the extracts (Table 1). This effect was previously described by Ratnasooriya and Rupasinghe (2012). As regards the extractions obtained by using ultrasound, the addition of $13 \mathrm{mM} \beta$ - or HP- $\beta$-CDs increased the value TPC up to $5.23 \mathrm{mg} /$ $\mathrm{g}_{\mathrm{db}}$ and $5.54 \mathrm{mg} / \mathrm{g}_{\mathrm{db}}$, respectively, representing an increase with respect to water extraction of $25 \%$ and $32 \%$, with an improvement in the antioxidant activity of the extracts of $33 \%$ and $75 \%$, respectively. It was observed that the increase in antioxidant activity of the extracts was not proportional to the increase in concentration of TPC extracted. The use of CDs not only improved the extraction of total phenolics with respect to water, but also the antioxidant activity of the phenolic compounds. In previous studies with pure phenolic compounds, some authors concluded that complexation with CDs increases the antioxidant capacity of encapsulated phenolic compounds (Lucas-Abellán et al., 2008; Mercader-Ros, Lucas-Abellán, Fortea, et al., 2010).

TPC and antioxidant activity of the extracts also increased with CDs concentration. Increasing $\beta$-CD concentration from 8 to $13 \mathrm{mM}$ had little effect on TPC and antioxidant activity, with statistical significant differences only between TPC of 8 and $13 \mathrm{mM}$ of $\beta-C D$ with ultrasound extraction. Increasing the concentration of HP- $\beta-C D s$ from 13 to $50 \mathrm{mM}$ the TPC extracted and antioxidant activity increased by around 30\%, with statistical significant differences between 13 and $50 \mathrm{mM}$ of $\mathrm{HP}-\beta-\mathrm{CD}$ in both stirring and ultrasound extractions.

Although the extraction of TPC and antioxidant activity using CDs was lower than that obtained by ethanol/water extraction, the addition of cyclic sugars improved TPC extraction and antioxidant activity compared with water extraction.

\subsection{HPLC identification and molecular model}

In order to determine the effect of CDs on the extraction of phenolic compounds, extracts were characterized by HPLC analysis. Fig. 1 shows four representative chromatograms of extracts obtained using ethanol/water (Fig. 1A), water (Fig. 1B), $\beta$-CDs $(13 \mathrm{mM})$ (Fig. 1C) and HP- $\beta$-CDs (13 mM) (Fig. 1D).

Identification of phenolic compounds by HPLC analysis showed the effect of CDs on the extraction of the main phenolic compounds gallic acid (1), catechin (2) and epicatechin (3). HPLC analysis has permitted to identify clearly catechin and epicatechin showing biggest signals for both compounds (Fig. 1A), while water led to

Table 1

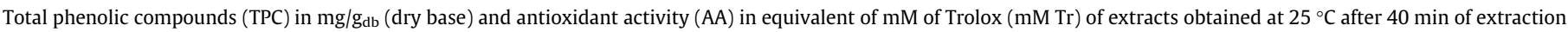

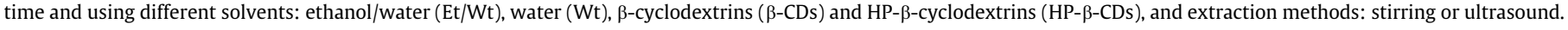

\begin{tabular}{|c|c|c|c|c|c|c|c|}
\hline \multirow[t]{2}{*}{ Solvent } & & \multicolumn{3}{|l|}{$\mathrm{TPC} \mathrm{mg} / \mathrm{g}_{\mathrm{db}}$} & \multicolumn{3}{|l|}{$\mathrm{AA} \mathrm{mM} \mathrm{Tr}$} \\
\hline & & Stirring & Ultrasound & S. S. & Stirring & Ultrasound & S. S. \\
\hline $\mathrm{Et} / \mathrm{Wt}$ & & $21.2 \pm 0.80^{\mathrm{d}}$ & $23.5 \pm 0.40^{d}$ & $*$ & $42.1 \pm 1.56^{\mathrm{d}}$ & $48.1 \pm 3.53^{\mathrm{e}}$ & $\mathrm{ns}$ \\
\hline Wt & & $3.67 \pm 0.24^{\mathrm{a}}$ & $4.18 \pm 0.14^{\mathrm{a}}$ & ns & $7.70 \pm 1.04^{\mathrm{a}}$ & $8.9 \pm 0.19^{a}$ & ns \\
\hline \multirow{2}{*}{$\beta$-CDs (mM) } & 8 & $4.34 \pm 0.10^{\mathrm{ab}}$ & $4.92 \pm 0.10^{\mathrm{a}}$ & $*$ & $9.80 \pm 0.15^{\mathrm{a}}$ & $11.2 \pm 0.58^{\mathrm{ab}}$ & $*$ \\
\hline & 13 & $4.45 \pm 0.33^{\mathrm{ab}}$ & $5.23 \pm 0.29^{b}$ & ns & $9.20 \pm 0.33^{\mathrm{ab}}$ & $11.9 \pm 1.75^{\mathrm{abc}}$ & ns \\
\hline \multirow[t]{3}{*}{$\mathrm{HP}-\beta-\mathrm{CDs}(\mathrm{mM})$} & 13 & $4.64 \pm 0.50^{\mathrm{ab}}$ & $5.54 \pm 0.26^{\mathrm{b}}$ & ns & $12.1 \pm 1.52^{\mathrm{b}}$ & $15.6 \pm 0.38^{\mathrm{bcd}}$ & ns \\
\hline & 25 & $5.09 \pm 0.30^{\mathrm{b}}$ & $5.89 \pm 0.53^{\mathrm{b}}$ & ns & $12.3 \pm 0.17^{\mathrm{b}}$ & $15.8 \pm 1.23^{\mathrm{cd}}$ & $*$ \\
\hline & 50 & $6.41 \pm 0.24^{\mathrm{c}}$ & $7.39 \pm 0.55^{c}$ & $*$ & $16.1 \pm 0.51^{\mathrm{c}}$ & $19.3 \pm 1.13^{\mathrm{d}}$ & $*$ \\
\hline
\end{tabular}

Values represent means of triplicate extraction $( \pm S D)$.

In each column, statistical difference between means is shown $(p<0.05)(a-e)$.

Statistical significance (S.S.) between stirring and ultrasound for TFC and AA: $\left(^{* *}\right) p<0.01 ;\left({ }^{*}\right) p<0,05$; (ns) no significant. 

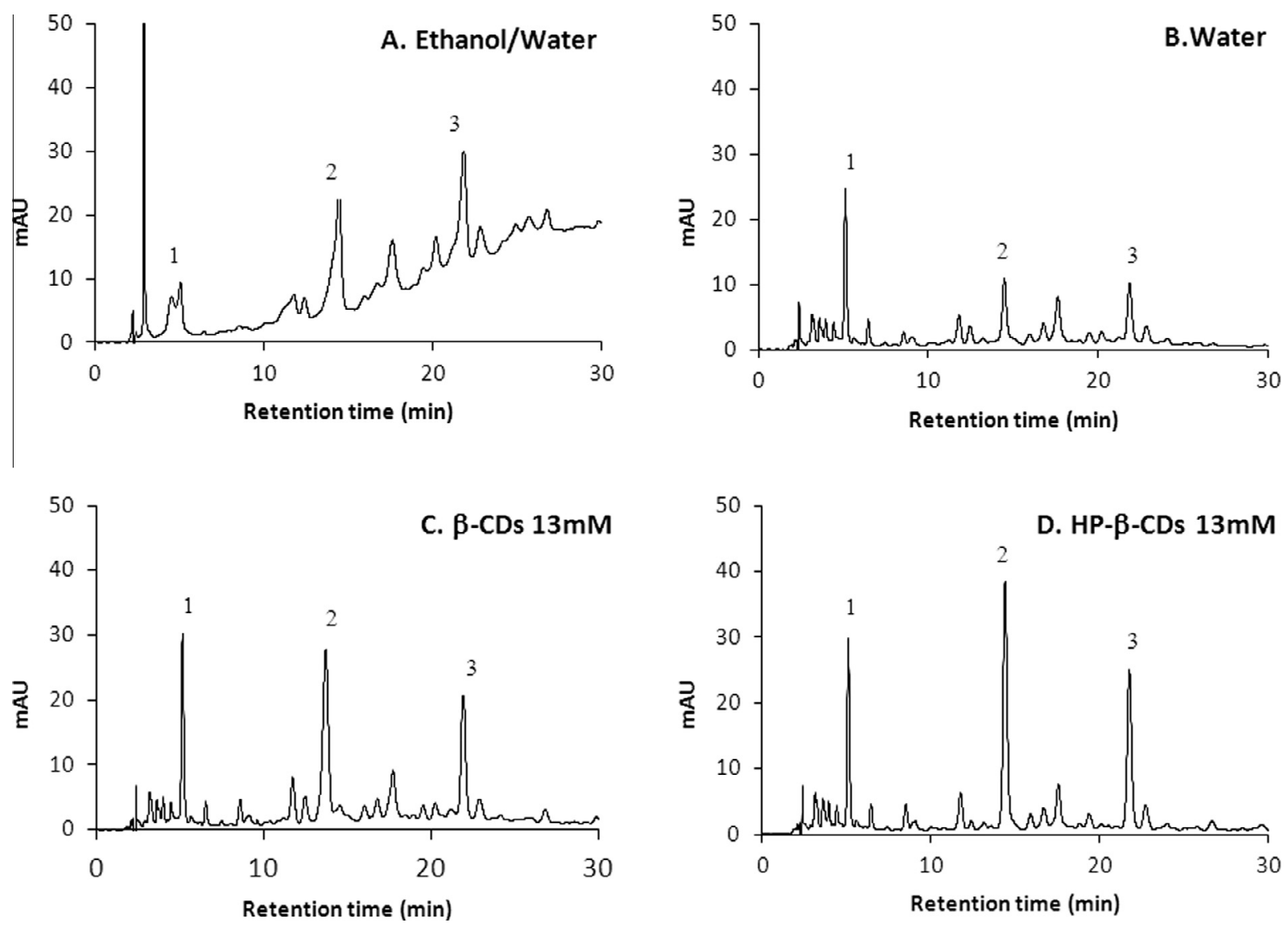

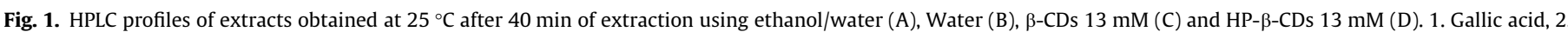
Catechin. 3. Epicatechin.

a significantly lower extraction, especially of compounds as catechin and epicatechin (Fig. 1B). However, the addition of CDs to the extraction water considerably increased catechin and epicatechin extraction (Fig. 1C and D). With respect to the signal detected by the HPLC, the area corresponding to catechin extracted in the presence of $\beta-C D$ or HP- $\beta$-CDs was 4 -fold that obtained by using water without CDs. In the case of epicatechin, the area detected by the HPLC was more than twice as large as water for both $\beta$ or HP- $\beta-C D$ s. These results show that catechin and epicatechin, due to their polarity and chemical structure, could be complexed in the hydrophobic cavity of CDs, forming soluble inclusion complexes that allow their selective extraction in aqueous medium.

In order to understand the interaction between catechin or epicatechin with $\beta$-CDs, docking simulations were carried out. The structural information about the non-covalent binding process obtained by docking for catechin and epicatechin is shown in Fig. 2. Both guest molecules fit well into the $\beta$-CDs hydrophobic cavity, where their hydrophobicity is more similar to that of the core. In addition, some of the polar groups of these molecules interact with $\beta-C D$ due mainly to electrostatic and hydrogen bond interactions.

\subsection{Catechin and epicatechin extraction}

To analyze the specific impact of CDs on catechin and epicatechin extraction, the type and concentration of CDs, extraction time, temperature and method (stirring and ultrasound) were studied.

Fig. 3A and B show the evolution of catechin and epicatechin extraction at $25^{\circ} \mathrm{C}$ using the stirring method, when ethanol/water, water, $\beta$-CDs $13 \mathrm{mM}$ or HP- $\beta$-CDs $13 \mathrm{mM}$ were used as extractant agents.
Catechin and epicatechin concentrations increased with extraction time for all the extracting agents used (Fig. 3A and B). The highest values were obtained at 90 min extraction time, reaching values around $1000 \mu \mathrm{g} / \mathrm{g}_{\mathrm{db}}$ for catechin (Fig. 3A) and $700-900 \mu \mathrm{g} /$ $\mathrm{g}_{\mathrm{db}}$ for epicatechin (Fig. 3B). These data were similar to those obtained by Iacopini et al. (2008) from grape skins, and lower than those observed by Maier et al. (2009) obtained from grape seed. Extraction was very fast during the first $10 \mathrm{~min}$ in the case of both compounds but then slowed down from 10 to 90 min of the extraction process (Fig. 3). This extraction dynamic was also described by Sánchez et al. (2008) and Bucic-Kojik et al. (2013). Water showed a very low extraction capacity for catechin and epicatechin compared with ethanol/water, providing values of $90 \mu \mathrm{g} / \mathrm{g}_{\mathrm{db}}$ and $108 \mu \mathrm{g} / \mathrm{g}_{\mathrm{db}}$ for catechin and epicatechin, respectively, after 90 min of extraction. These values are higher than those obtained by Ratnasooriya and Rupasinghe (2012).

With respect to catechin extraction, statistical significant differences between CDs solutions ( $\beta$ - or HP- $\beta$-CDs) and ethanol/water were only observed at $10 \mathrm{~min}$ of extraction (Fig. 3A). Ethanol/water led to slightly higher catechin extraction values than those obtained using $\beta$ - or HP- $\beta$-CDs, but greater than $16 \%$ and $14 \%$, respectively, at $40 \mathrm{~min}$ (Fig. $3 \mathrm{~A}$ ). At $90 \mathrm{~min}$ of extraction, no statistical significant differences between ethanol/water and CDs extractions were observed.

In the case of epicatechin, the best extracting agent was HP$\beta$-CDs, followed by ethanol/water and $\beta$-CDs (Fig. 3B). By $90 \mathrm{~min}$, the HP- $\beta-\mathrm{CDs}$ solution had extracted $13 \%$ more epicatechin than ethanol/water, and no statistical significant differences between ethanol/water and $\beta$-CDs extraction were observed (Fig. 3B). 

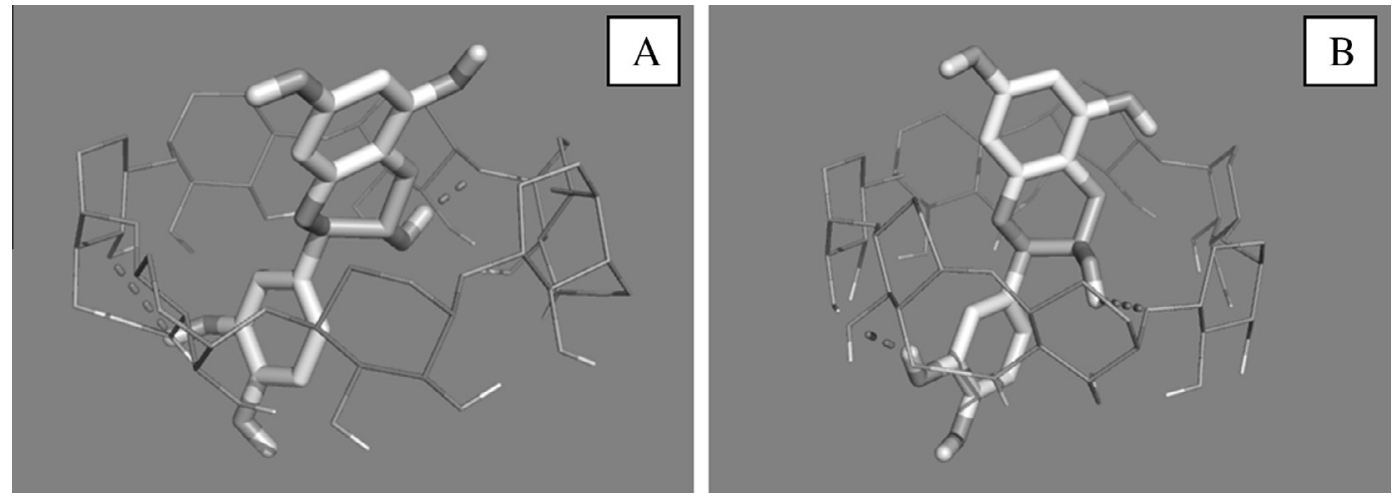

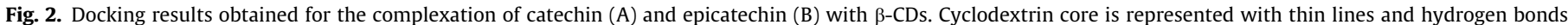
with yellow dashes. (For interpretation of the references to color in this figure legend, the reader is referred to the web version of this article.)
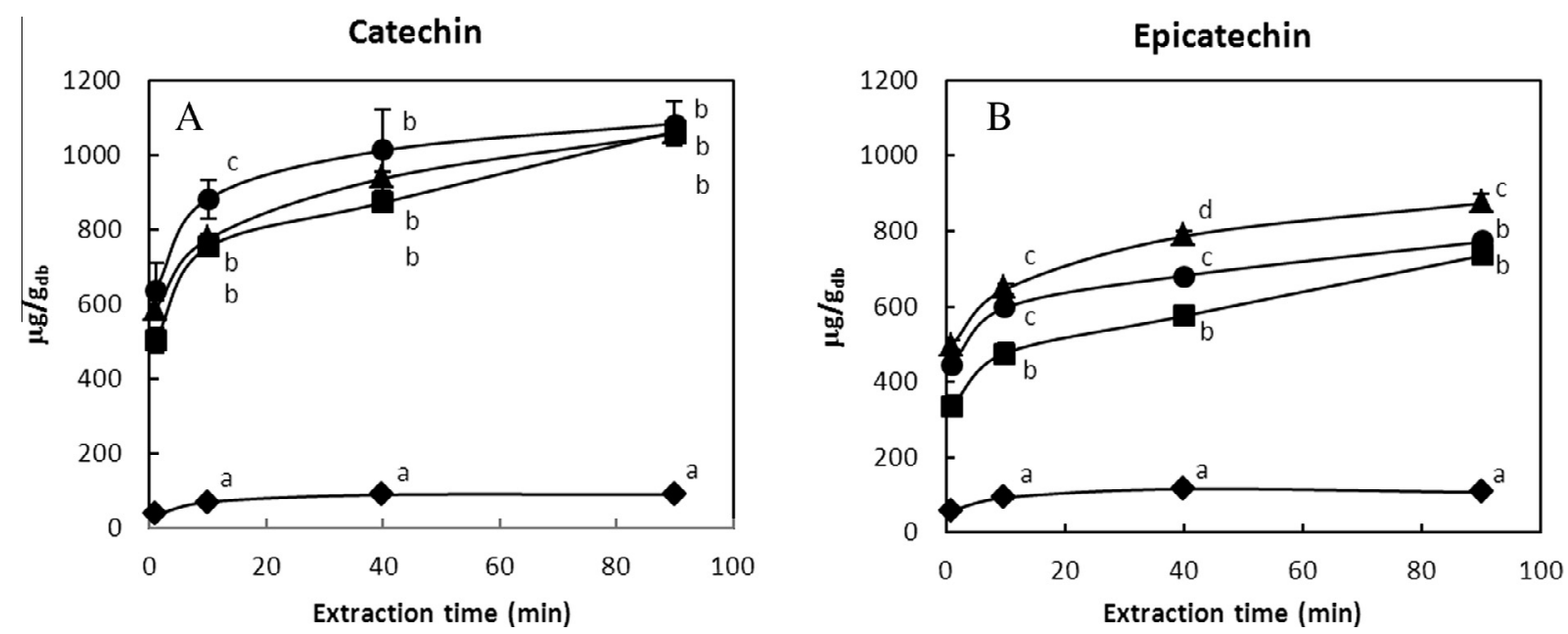

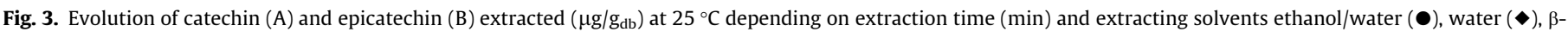

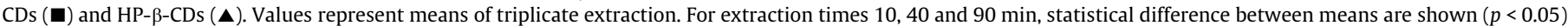
$(\mathrm{a}-\mathrm{d})$.

The temperature was also an important factor during the solidliquid extraction process. Only moderate temperatures are suitable in order to prevent damage or negatively effect on phenolic compounds and their biological activity (Bucic-Kojic et al., 2013). Extractions of catechin and epicatechinat $40^{\circ} \mathrm{C}$ are shown in Fig. $4 \mathrm{~A}$ and $\mathrm{B}$.

Catechin and epicatechin extraction increased with the extraction time at $40{ }^{\circ} \mathrm{C}$, being more intense during the first $10 \mathrm{~min}$, after which the extraction rate became more moderate (Fig. 4). At $40{ }^{\circ} \mathrm{C}$, there were significant differences in the amount of catechin and epicatechin extracted between water and CDs solutions.

Regarding to the extraction of catechin, there were no statistical significant differences between $\beta$ - and HP- $\beta$-CDs. Extraction with $\beta$-CDs at $40{ }^{\circ} \mathrm{C}$ reached a maximum of $1348 \mu \mathrm{g} / \mathrm{g}_{\mathrm{db}}$, representing a $26 \%$ increase compared with extraction at $25^{\circ} \mathrm{C}$. Extraction with $\mathrm{HP}-\beta-\mathrm{CD}$ reached a maximum of $1467 \mu \mathrm{g} / \mathrm{g}_{\mathrm{db}}$, which represents $39 \%$ of increase in relation to extraction at $25^{\circ} \mathrm{C}$.

In the case of epicatechin, maximum extraction were $896 \mu \mathrm{g} /$ $\mathrm{g}_{\mathrm{db}}$ for $\beta$-CDs and $1112 \mu \mathrm{g} / \mathrm{g}_{\mathrm{db}}$ for HP- $\beta$-CDs, which represents an increase of $22 \%$ and $27 \%$, respectively, in relation with extraction observed at $25{ }^{\circ} \mathrm{C}$. It could be observed statistical significant differences between $\beta$ - and HP- $\beta$-CDs from 10 to $90 \mathrm{~min}$ of extraction time.

These results demonstrated that catechin and epicatechin could be extracted from grape pomace by using CDs aqueous solutions, reaching similar level of extraction than using ethanol/water as extraction solvent.

Finally, the effect of the type of energy applied, stirring or ultrasound, to extract catechin and epicatechin from grape pomace was studied. Fig. 5A and B show the extraction of catechin and epicatechin in the presence of $\beta$ - or HP- $\beta$-CDs, as well as water or ethanol/water, using stirring or ultrasound as energy source, at $25^{\circ} \mathrm{C}$ for $40 \mathrm{~min}$.

As can be seen in Fig. 5A and B, with respect to the extraction method, the trend was similar to that observed for TPC (Table 1). The yield obtained with ultrasound (Fig. 5, dark gray bars) was slightly higher than with stirring (Fig. 5, light gray bars). On average, the improvement in catechin and epicatechin extraction obtained by using ultrasound was around $12 \%$ for all the extraction agents except for water, in which case, the increase was $119 \%$ and $109 \%$ for catechin and epicatechin, respectively.

An increase in CDs concentration also improved catechin and epicatechin extraction in both methods, as was observed in the case of TPC (Table 1 ).

\section{Conclusions}

It can be concluded that CDs can be used as an alternative to organic solvents for the extraction of phenolic compounds, espe- 
Catechin

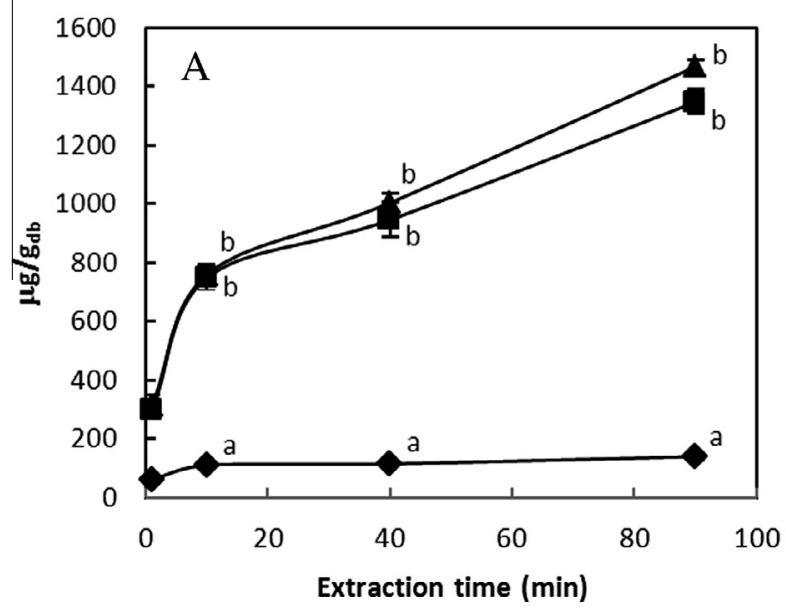

Epicatechin

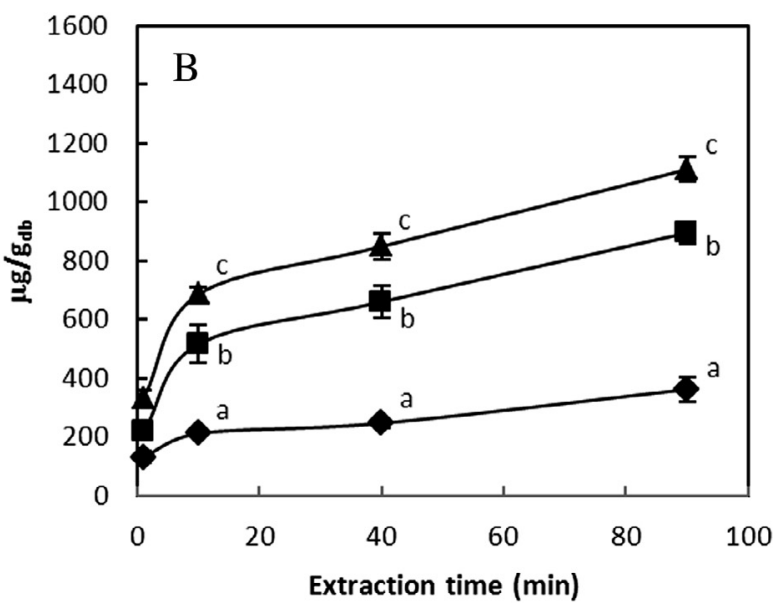

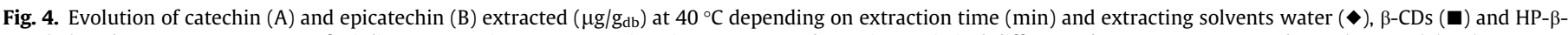
CDs $(\boldsymbol{\Delta})$. Values represent means of triplicate extraction. For extraction times 10, 40 and 90 min, statistical difference between means are shown ( $p<0.05)(a-c)$.
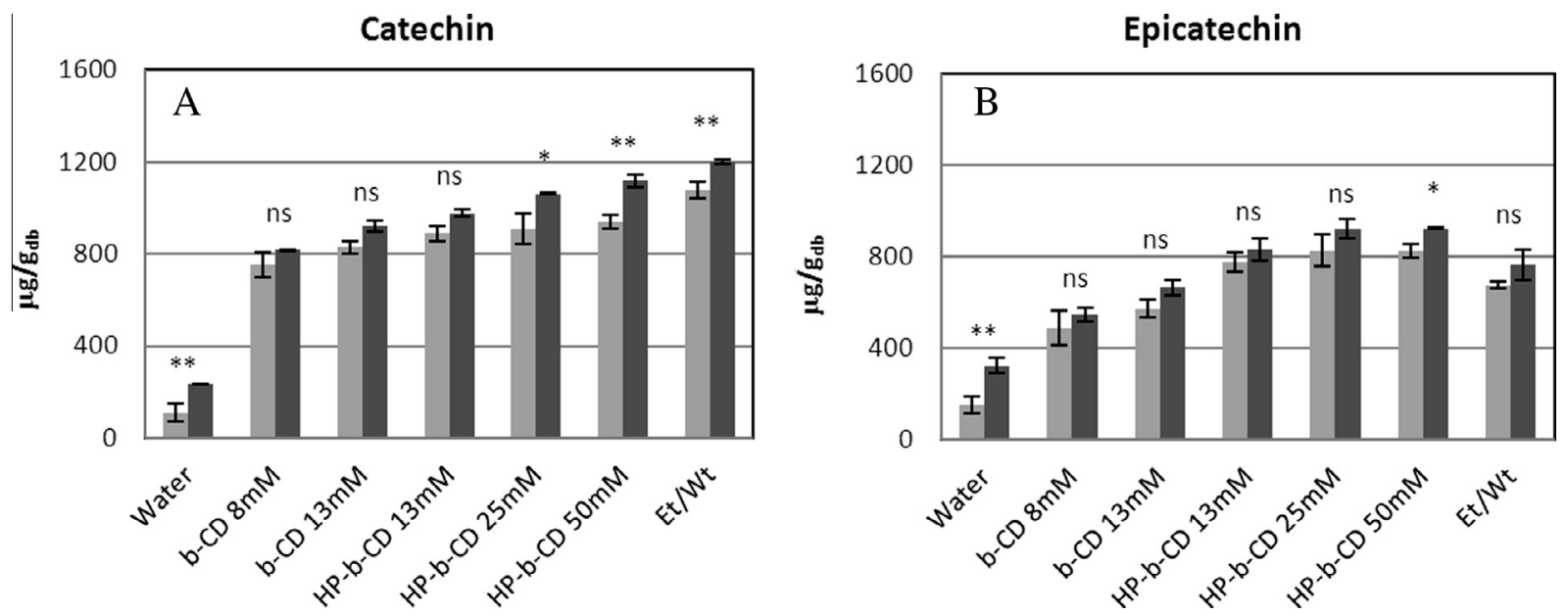

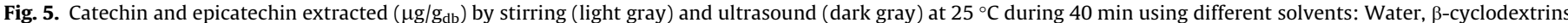

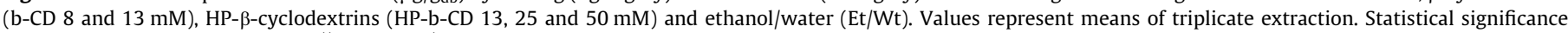
between stirring and ultrasound: $\left({ }^{* *}\right) p<0.01 ;\left({ }^{*}\right) p<0.05$; (ns) no significant.

cially catechin and epicatechin. The extraction yield of catechin and epicatechin using aqueous solutions of CDs was similar to that obtained using organic solvents such as ethanol. So, CDs could be considered a viable solution for the selective extraction of some interesting phenolic compounds from grape pomace.

\section{Acknowledgments}

This research was supported by the Agencia de Ciencia y Tecnología de la Región de Murcia under the project PFEseneca/06/10 and Bodegas San Isidro in Jumilla (Spain).

\section{References}

Arvanitoyannis, I., Ladas, D., \& Mavromatis, A. (2006). Potential uses and applications of treated wine waste: a review. International Journal of Food Science and Technology, 41, 475-487.

Bucic-Kojic, A., Sovová, H., Planinic, M., \& Srecko, T. (2013). Temperature-dependent kinetics of grape seed phenolic compounds extraction: Experiment and model. Food Chemistry, 136, 1136-1140.

Bustamante, M. A., Moral, R., Paredes, C., Pérez-Espinosa, A., Moreno-Caselles, J., \& Pérez-Murcia, M. D. (2008). Agrochemical characterisation of the solid byproducts and residues from the winery and distillery industry. Waste Management, 28, 372-380.
Chedea, V. S., Braicu, C., \& Socaciu, C. (2010). Antioxidant/prooxidant activity of a polyphenolic grape seed extract. Food Chemistry, 121, 132-139.

Da Porto, C., Natolino, A., \& Decorti, D. (2014). Extraction of proanthocyanidins from grape marc by supercritical fluid extraction using $\mathrm{CO}_{2}$ as solvent and ethanolwater mixture as co-solvent. The Journal of Supercritical Fluids, 87, 59-64.

Dávalvos, A., Gómez-Cordovés, C., \& Bartolomé, B. (2004). Extending applicability of the oxygen radical absorbance capacity (ORAC-fluorescein) assay. Journal of Agricultural and Food Science, 52, 48-54.

Herrero, M., Cifuentes, A., \& Ibañez, E. (2006). Sub- and supercritical fluid extraction of functional ingredients from different natural sources: Plants, food-byproducts, algae and microalgae: A review. Food Chemistry, 98, 136-148.

Iacopini, P., Baldi, M., Storchi, P., \& Sebastiani, L. (2008). Catechin, epicatechin, quercetin, rutin and resveratrol in red grape: Content, in vitro antioxidant activity and interactions. Journal of Food Composition and Analysis, 21, 589-598.

Jang, M., Cai, L., Udeani, G. O., Slowing, K. V., Thomas, C. F., Beecher, C. W., ... Pezzuto J. M. (1997). Cancer chemopreventive activity of resveratrol, a natural product derived from grapes. Science, 275, 217-220.

Kammerer, D., \& Kljusuric, J. G. (2005). Recovery of anthocyanins from grape pomace extracts (Vitis vinivera L. cv. Cabernet Mitos) using a polymeric adsorber resin. European Food Research and Technology, 220, 431-437.

Kennedy, J. A., Saucier, C., \& Glories, Y. (2005). Grape and wine phenolics: History and perspective. American Journal of Enology and Viticulture, 57, 239-248.

Kidron, M., Harel, E., \& Mayer, A. M. (1978). Catechol oxidase activity in grapes and wine. American Journal of Enology and Viticulture, 29, 30-35.

Kuroda, Y., \& Hara, Y. (1999). Antimutagenic and anticarcinogenic activity of tea polyphenols. Mutation Research, 97, 436-469.

Lafka, T., Sinanoglou, V., \& Lazos, E. (2007). On the extraction and antioxidant activity of phenolic compounds from winery wastes. Food Chemistry, 104, 1206-1214. 
Louli, V., Ragoussis, N., \& Magoulas, K. (2004). Recovery of phenolic antioxidants from wine industry by-products. Bioresource Technology, 92, 201-208.

Lucas-Abellán, C., Fortea, M. I., Gabalón, J. A., \& Núñez-Delicado, E. (2008). Complexation of resveratrol by native and modified cyclodextrins: Determinations of complexation constant by enzymatic, solubility and fluorimetric assays. Food Chemistry, 111, 262-267.

Maier, Th., Schieber, A., Kammerer, R., \& Carle, R. (2009). Residues of grape (Vitis vinifera L.) seed oil production as a valuable source of phenolic antioxidants. Food Chemistry, 112, 551-559.

Makris, D., Boskou, G., \& Andrikopoulos, N. K. (2007). Recovery of antioxidant phenolics from white vinification solid by-products employing water/ethanol mixtures. Bioresource Technology, 98, 2963-2967.

Mercader-Ros, M. T., Lucas-Abellán, C., Fortea, M. I., Gabaldón, J. A., \& NúñezDelicado, E. (2010). Effect of HP- $\beta$-cyclodextrins complexation on the antioxidant activity of flavonols. Food Chemistry, 118, 769-773.

Mercader-Ros, M. T., Lucas-Abellán, C., Gabaldón, J. A., Fortea, M. I., Martínez-Cachá, A., \& Núñez-Delicado, E. (2010). Kaempferol complexation in cyclodextrins at basic pH. Journal of Agricultural and Food Chemistry, 58, 4675-4680.
Morris, G. M., Huey, R., Lindstrom, W., Sanner, M. F., Belew, R. K., Goodsell, D. S., \& Olson, A. J. (2009). AutoDock4 and AutoDockTools4: Automated docking with selective receptor flexibility. Journal of Computational Chemistry, 30, 2785-2791.

Negro, C., Tommasi, L., \& Miceli, A. (2003). Phenolic compounds and antioxidant activity from red grape marc extracts. Bioresource Technology, 87, 41-44.

Ratnasooriya, Ch., \& Rupasinghe, H. P. (2012). Extraction of phenolic compounds from grapes and their pomace using b-cyclodextrin. Food Chemistry, 134, 625-631.

Sánchez, M., Sineriro, J., \& Núñez, M. J. (2008). Extraction of polyphenols from white distilled grape pomace: Optimization and modelling. Bioresource Technology, 99, $1311-1318$.

Shrikhande, A. (2000). Wine by-products with health benefits. Food Research International, 33, 469-474.

Trott, O., \& Olson, A. J. (2010). AutoDock Vina: Improving the speed and accuracy of docking with a new scoring function, efficient optimization, and multithreading. Journal of Computational Chemistry, 31, 455-461.

Tsanova-Savova, S., Ribarova, F., \& Gerova, M. (2005). Catequin and epicatequin in Bulgarian fruits. Journal of Food Composition and Analysis, 18, 691-698. 